\title{
A relação entre a vida acadêmica e a vida familiar do estudante de medicina: uma análise transversal
}

\author{
The relationship between academic life \\ and family life of the medicine student: \\ A cross-sectional analysis
}

\section{Steffany Barbosa Reis ${ }^{1}$ (I) Carolina Villa Nova Aguiar ${ }^{2}$ (1)}

1'Autora para correspondência. Escola Bahiana de Medicina e Saúde Pública (Salvador). Bahia, Brasil. steffanyreis17.2@bahiana.edu.br ${ }^{2}$ Escola Bahiana de Medicina e Saúde Pública (Salvador). Bahia, Brasil. carolinaaguiar@bahiana.edu.br

RESUMO | INTRODUÇÃO: Conciliar demandas acadêmicas e demandas oriundas de outras esferas da vida pode ser um obstáculo para estudantes, o que torna relevante a investigação sobre as relações estabelecidas entre a vida acadêmica e a vida familiar dos estudantes de medicina. OBJETIVOS: Desenvolver e reunir evidências de validade de escalas para mensuração das interfaces entre a vida acadêmica e vida familiar de estudantes e descrever a percepção sobre as interfaces estabelecidas entre elas. MÉTODOS E MATERIAIS: Escalas existentes e validadas sobre interface positiva e conflito trabalho-família foram adaptadas para escalas para avaliação das interfaces entre vida acadêmica e vida familiar. Foram conduzidas análises fatoriais exploratórias, além de verificação da confiabilidade interna. Os resultados das escalas foram descritos por meio de médias e desvio-padrão. RESULTADOS: As escalas adaptadas foram aplicadas a 539 estudantes de medicina. $\mathrm{Na}$ Escala de Conflito Estudos-Família, o fator "Conflito Estudos-Família" reuniu 5 itens (alpha $=0,78$ ) e o fator "Conflito Família-Estudos" reuniu 7 itens (alpha= 0,85$)$. As médias obtidas foram 3,97( $\pm 1,03)$ e $2,57( \pm 1,09)$, respectivamente. Com relação à Escala da Interface Positiva EstudosFamília, o fator "Interface Positiva Família-Estudos" reuniu 7 itens (alpha $=0,90$ ) e o fator "Interface Positiva Estudos-Família" reuniu 6 itens (alpha $=0,85$ ). As médias obtidas foram $4,95( \pm 0,96)$ e $2,57( \pm 1,06)$, respectivamente. CONCLUSÃO: Os instrumentos propostos mostraramse válidos e confiáveis para mensurar as interfaces positiva e negativa entre a vida acadêmica e a vida familiar de estudantes. Os estudantes de medicina identificam uma maior influência da vida acadêmica prejudicando a vida familiar e percebem a família contribuindo mais nos estudos de maneira favorável.

PALAVRAS-CHAVE: Educação. Família. Medicina. Qualidade de Vida. Estudo de Validação.
ABSTRACT | INTRODUCTION: Given the characteristics of the medical course, we seek to understand the quality of life of the student, aiming to understand the physical, emotional, and subjective well-being of these individuals. Within this context is the family, which is an important domain of social organizations, subject to generating changes and being modified in the context of reconciling academic and family life. OBJECTIVES: To develop and gather evidence of the validity of scales to measure the interfaces between academic and family life of students and describe the perception about the interfaces established between them. METHODS AND MATERIALS: Adaptation of existing and validated scales on a positive interface and work-family conflict was carried out to build scales for evaluating students' academic and family life in the health area. Exploratory and confirmatory factor analyzes were carried out, as well as elements to verify internal reliability. The results of the scales were described using means and standard deviation. RESULTS: In the Family-Studies Conflict Scale, the correlation matrix obtained showed $\mathrm{KMO}=0.809$, and Bartlett's sphericity test was significant. The "Family-Study Conflict" factor showed a Cronbach's alpha of 0.78. The "Family-Study Conflict" factor, on the other hand, had an alpha of 0.85 . Regarding the Positive Family-Family Interface Scale, the correlation matrix obtained showed $\mathrm{KMO}=0.861$, and Bartlett's sphericity test was significant. The factor "Positive Family-Study Interface" showed an alpha of 0.90 . The factor "Positive Interface Studies-Family" showed an alpha of 0.85 . The instrument was applied to a sample of 539 medical students who perceived a greater conflict in academic life in the family. CONCLUSION: The adaptation of scales to validate instruments was able to assess the positive and negative relationships between family studies. The conflict motivated by academic life in family life represents the phenomenon most perceived by medical students.

KEYWORDS: Education. Family. Medicine. Quality of Life. Validation Study. 


\section{Introdução}

O curso de medicina no Brasil dura seis anos e é dividido tradicionalmente em ciclo básico, ciclo profissionalizante e internato. No ciclo básico, são expostas aos alunos as disciplinas elementares para compreensão dos processos físicos e biológicos em um período de dois anos. O ciclo profissionalizante, também conhecido como ciclo clínico, abrange as quatro grandes especialidades: Clínica Médica, Cirurgia, Pediatria e Ginecologia-Obstetrícia. Nesse momento, o acadêmico aprende sobre a prática clínica e os processos patológicos, também durando dois anos. Por fim, os dois últimos anos englobam o internato em que o estudante se encontra em estágios supervisionados por docentes nas mais diversas especialidades, em todos os níveis de atenção à saúde. ${ }^{1}$ Para desenvolver as habilidades requeridas pela profissão dentro dos seis anos previstos, é necessária uma extensa carga horária no curso e, além das obrigações formativas, o acadêmico participa de atividades extracurriculares, como monitorias, grupos de iniciação científica, estágios, extensão universitária, prolongando consideravelmente as horas destinadas aos estudos.

Diante das características e peculiaridades que envolvem o curso de medicina, muitos pesquisadores passaram a explorar a qualidade de vida do estudante de medicina. Isso se deve ao fato de haver preocupação com o bem-estar físico, emocional e subjetivo desses indivíduos, assim como o impacto que tais fatores podem gerar no exercício da profissão.?

A qualidade de vida engloba e sofre influência de múltiplas variáveis, incluindo condições internas e externas, estando, entre elas, a inserção e participação em instituições sociais, como a família e as Instituições de Ensino Superior (IES). A família configura-se como uma esfera significativa na vida dos indivíduos, sendo considerada o mais importante microssistema para desenvolvimento dos sujeitos e interação entre eles. De forma complementar, as IES também são vistas como um microssistema expressivo para o crescimento e amadurecimento de uma pessoa, por exigirem comunicação e convívio com professores e colegas, além de contribuírem para a formação da identidade profissional dos sujeitos. ${ }^{3}$

Apesar do amplo interesse em torno da qualidade de vida do estudante de medicina e da reconhecida importância exercida tanto pela família quanto pelo ambiente acadêmico na formação geral dos sujeitos, ainda existe um hiato na literatura quando se trata de investigar as relações estabelecidas entre a vida acadêmica e a vida familiar dos estudantes de medicina. O presente trabalho pretende, portanto, descrever como esses estudantes percebem as interfaces estabelecidas entre as suas vidas acadêmicas e familiares. Entretanto, tendo em vista a ausência na literatura de instrumentos para mensurar o fenômeno em questão, será conduzido, como um objetivo preliminar desse estudo, o desenvolvimento e reunião de evidências de validade de escalas para a mensuração das interfaces entre a vida acadêmica e a vida familiar de estudantes.

\section{Metodologia}

Para alcançar os objetivos, duas etapas metodológicas foram traçadas: a primeira pretendeu propor as versões iniciais das escalas para avaliação das interfaces entre vida acadêmica e vida familiar de estudantes da área da saúde; a segunda consistiu na avaliação das propriedades psicométricas das escalas propostas e descrição dos seus resultados obtidos quando aplicadas a uma amostra de estudantes de medicina de diversas IES.

\section{Etapa 1: Proposta de instrumento}

Para a etapa de construção da versão inicial do instrumento, optou-se por realizar a adaptação de escalas já existentes e previamente validadas para a investigação das interfaces estabelecidas entre o trabalho e a família. Para isso, foram adotados os seguintes instrumentos: 
A) Escala Multidimensional de Conflito TrabalhoFamília4: trata-se de uma escala composta por duas dimensões: interferência do trabalho na família (8 itens, exemplo de item: meu trabalho me afasta de minhas atividades familiares mais tempo do que eu gostaria) e interferência da família no trabalho (8 itens, exemplo de item: o tempo que eu gasto com responsabilidades familiares frequentemente interfere nas minhas responsabilidades no trabalho).

B) Escala de Interface Positiva entre Trabalho e Família trata-se de uma escala bidimensional composta por 19 itens. O primeiro fator refere-se à interface positiva trabalho-família, que abrange 9 itens (exemplo de item: os comportamentos exigidos no trabalho levam a comportamentos que me ajudam na vida familiar). O segundo fator refere-se à interface positiva família-trabalho, que abarca 10 itens (exemplo de item: por causa de tudo que tenho a meu favor na minha família, meu humor melhora no trabalho).

Para ambas as escalas, utilizou-se uma escala do tipo Likert de 6 pontos, sendo construída da seguinte forma: 1 = Discordo totalmente, 2 = Discordo muito, 3 = Discordo pouco, 4 = Concordo pouco, 5 = Concordo muito, $6=$ Concordo totalmente.

A adaptação dos itens para o novo contexto (interfaces entre vida acadêmica e vida familiar) foi feita pelas pesquisadoras do grupo de pesquisa e, em seguida, enviada para um painel composto por 10 juízes (grupo integrado por médicos, fisioterapeutas, psicólogos e enfermeira, todos docentes de cursos de graduação da área de saúde e pesquisadores de áreas afins ao escopo do trabalho). Seguindo o modelo recomendado por Borsa e Seize ${ }^{6}$, foi enviado um questionário para que os juízes pudessem avaliar cada um dos indicadores por meio de uma escala do tipo Likert (1 = não relevante ou não representativo; 2 = item necessita de grande revisão para ser representativo; 3 = item necessita de pequena revisão para ser representativo; 4 = item relevante ou representativo).
A partir das respostas oferecidas, foram calculados os índices de validade de conteúdo (IVC) com base nas recomendações de Alexandre e Coluci. ${ }^{7}$ Foram considerados insatisfatórios índices abaixo de 0,78.

Após a realização de ajustes apontados pelos juízes, procedeu-se à etapa de validação semântica, na qual foi solicitado a um pequeno grupo de 22 estudantes do curso de medicina que julgassem os itens das escalas em termos de responsividade, clareza e objetividade. Mais uma vez, foram calculados os IVCs e realizados ajustes na redação dos itens. Tal etapa de pesquisa resultou na proposta de uma primeira versão do instrumento, que foi aplicada em uma ampla amostra de estudantes após aprovação do Comitê de Ética em Pesquisa (CEP).

\section{Etapa 2: Avaliação da qualidade psicométrica do instrumento e descrição dos resultados}

Nesta etapa, a escala adaptada foi aplicada a uma amostra de estudantes de medicina e passou pelas etapas de validação de constructo e de análise de confiabilidade.

\section{Participantes}

Foram convidados a participar do estudo estudantes do curso de medicina de diferentes Instituições de Ensino Superior (IES), por todo o país, podendo ser instituições públicas ou privadas. Os critérios de inclusão foram estudante de medicina e ter 18 anos ou mais; e o critério de exclusão foi o estudante não estar regular no curso, ou seja, estar afastado por trancamento de matrícula ou qualquer outro motivo.

\section{Instrumento de pesquisa e procedimentos de coleta de dados}

O instrumento de pesquisa foi composto por duas seções: a primeira contemplou a caracterização pessoal e ocupacional do participante (exemplo: gênero, estado civil, escolaridade, responsabilidade financeira pela manutenção da família) e a segunda foi composta pelas escalas adaptadas. 
Os participantes foram convidados a participar através de um link divulgado via e-mail e WhatsApp. Os estudantes foram recrutados, inicialmente, pelas redes de relacionamentos das pesquisadoras envolvidas no projeto e, para maior alcance e variabilidade da amostra, foi adotada a técnica de bola de neve para divulgação mais ampla da pesquisa. Em caso de aceite, o participante deveria acessar um link da plataforma GoogleForms no qual foram disponibilizados o Termo de Consentimento Livre e Esclarecido (TCLE) e o instrumento de pesquisa.

\section{Procedimentos de análise}

Para validação, foram conduzidas análises fatoriais exploratórias (AFE) utilizando o método de extração Principal Axis Factoring (PAF) e rotação oblíqua do tipo Direct Oblimin. Inicialmente, foram observados os valores do teste Kaiser-Meyer-Olkin (KMO) (sendo satisfatórios valores acima de 0,500) e do teste de esfericidade de Bartlett (sendo aceitáveis valores significativos, com $p<0,05$ ). Em seguida, foram adotados os critérios da raiz latente e a priori para a estimação do número de fatores a serem retidos. As soluções fatoriais encontradas foram analisadas a partir das cargas fatoriais alcançadas, além de observadas a presença de baixa representatividade (carga fatorial abaixo de 0,30 ), de ambiguidades fatoriais (cargas fatoriais semelhantes para mais de um fator) ou, ainda, de inconsistências empíricas (itens alocados empiricamente em fator diferente do previsto teoricamente). $\underline{\cdot}$
Para a verificação da confiabilidade interna, foram calculados os coeficientes alpha de Cronbach e de confiabilidade composta, sendo considerados aceitáveis valores a partir de 0,70 e de alta confiabilidade os índices a partir de $0,80.10$

Após os procedimentos de validação, os resultados das escalas foram descritos por meio de médias e desvio-padrão. Para a comparação dos resultados por ciclo do curso, foram realizadas análises de comparação de média (ANOVA) e utilizado o teste post hoc de Bonferroni. Foram considerados significativos valores de $p<0,05$.

\section{Questões éticas}

Por se tratar de pesquisa com envolvimento de seres humanos, o projeto foi enviado para apreciação Comitê de Ética em Pesquisa da Escola Bahiana de Medicina e Saúde Pública, sendo aprovado em 27 de maio de 2020 sob o número de parecer 4.052 .521 e CAEE 30683920.1.0000.5544.

\section{Resultados}

\section{Etapa 1: Adaptação de escalas}

A primeira etapa do processo de adaptação se deu através da construção de uma escala a partir de instrumentos existentes utilizados para medir a interface positiva e a interface negativa da relação trabalho-família. Os resultados encontram-se nos Quadros 1 e 2. 


\begin{tabular}{|c|c|}
\hline Item & Item adaptado \\
\hline Conflito Trabalho-Família & Conflito Estudos-Família \\
\hline $\begin{array}{l}\text { Meu trabalho me afasta de minhas atividades familiares mais tempo } \\
\text { do que eu gostaria. } \\
\text { Eu muito frequentemente me sinto tão emocionalmente sugado pelo } \\
\text { meu trabalho que isso me impede de contribuir com a minha família. } \\
\text { Os comportamentos que utilizo para solucionar problemas no } \\
\text { trabalho não são efetivos para solucionar os problemas de casa. } \\
\text { O tempo que eu devo me dedicar ao trabalho me impede de } \\
\text { participar igualmente das atividades e responsabilidades em casa. } \\
\text { Quando eu chego em casa do trabalho, muitas vezes eu já estou } \\
\text { muito esgotado para participar das atividades familiares. } \\
\text { Devido às pressões do trabalho, algumas vezes eu chego em casa } \\
\text { muito estressado para fazer as coisas que gosto. } \\
\text { Eu deixo de fazer coisas com a minha família devido ao tempo que } \\
\text { preciso dedicar ao meu trabalho. } \\
\text { Os comportamentos que desempenho para ser eficaz no trabalho } \\
\text { não me ajudam a ser uma pessoa melhor para a minha família } \\
\text { (melhor pai/mãe; marido/esposa). }\end{array}$ & $\begin{array}{l}\text { Meus estudos me afastam das minhas atividades familiares mais } \\
\text { tempo do que eu gostaria. } \\
\text { Eu muito frequentemente me sinto tão emocionalmente sugado(a) } \\
\text { pela minha vida acadêmica que isso me impede de contribuir com a } \\
\text { minha família. } \\
\text { Os comportamentos que utilizo para solucionar problemas no } \\
\text { ambiente acadêmico não são efetivos para solucionar os problemas } \\
\text { de casa. } \\
\text { O tempo que eu preciso me dedicar aos estudos me impede de } \\
\text { participar igualmente das atividades e responsabilidades em casa. } \\
\text { Quando eu concluo as minhas atividades acadêmicas, muitas vezes } \\
\text { eu já estou muito esgotado(a) para participar das atividades } \\
\text { familiares. } \\
\text { Devido às pressões acadêmicas, algumas vezes eu chego em casa } \\
\text { muito estressado(a) para fazer as coisas que eu gosto. } \\
\text { Eu deixo de fazer coisas com a minha família devido ao tempo que } \\
\text { preciso dedicar às atividades acadêmicas. } \\
\text { Os comportamentos que desempenho para ser eficaz no ambiente } \\
\text { acadêmico não me ajudam a ser uma pessoa melhor para a minha } \\
\text { família (melhor filho/filha; pai/mãe; marido/esposa). }\end{array}$ \\
\hline & Conflito Família-Estudo \\
\hline $\begin{array}{l}\text { o tempo que eu gasto com responsabilidades familiares } \\
\text { frequentemente interfere nas minhas responsabilidades no trabalho. } \\
\text { Devido ao estresse que vivo em casa, eu frequentemente fico } \\
\text { preocupado com problemas familiares no trabalho. } \\
\text { O tempo que passo com minha família frequentemente me impede } \\
\text { de dedicar tempo a atividades no trabalho que poderiam ajudar na } \\
\text { minha carreira. } \\
\text { Como eu frequentemente estou estressado por causa das minhas } \\
\text { responsabilidades familiares, eu tenho dificuldade de me concentrar } \\
\text { no meu trabalho. } \\
\text { Os comportamentos que funcionam para mim em casa não são } \\
\text { eficazes no meu trabalho. } \\
\text { A tensão e a ansiedade vindas da minha família frequentemente } \\
\text { enfraquecem minha capacidade de fazer meu trabalho. } \\
\text { Eu deixo de fazer tarefas do trabalho devido à quantidade de tempo } \\
\text { que preciso dedicar às minhas responsabilidades familiares. } \\
\text { Os comportamentos que uso para resolver problemas em casa não } \\
\text { são úteis no trabalho. }\end{array}$ & $\begin{array}{l}\text { O tempo que eu gasto com responsabilidades familiares } \\
\text { frequentemente interfere nas minhas responsabilidades } \\
\text { acadêmicas. } \\
\text { Devido ao estresse que vivo em casa, eu frequentemente fico } \\
\text { preocupado(a) com problemas familiares enquanto me dedico às } \\
\text { atividades acadêmicas. } \\
\text { O tempo que passo com minha família frequentemente me impede } \\
\text { de dedicar tempo a atividades acadêmicas que poderiam ajudar na } \\
\text { minha carreira. } \\
\text { Como eu frequentemente estou estressado(a) por causa das minhas } \\
\text { responsabilidades familiares, eu tenho dificuldade de me concentrar } \\
\text { nos meus estudos. } \\
\text { Os comportamentos que funcionam para mim em casa não são } \\
\text { eficazes no meu espaço acadêmico. } \\
\text { A tensão e a ansiedade vindas da minha família frequentemente } \\
\text { enfraquecem minha capacidade de cumprir minhas atividades } \\
\text { acadêmicas. } \\
\text { Eu deixo de fazer atividades acadêmicas devido à quantidade de } \\
\text { tempo que preciso dedicar às minhas responsabilidades familiares. } \\
\text { Os comportamentos que uso para resolver problemas em casa não } \\
\text { são úteis no ambiente acadêmico. }\end{array}$ \\
\hline
\end{tabular}

Fonte: Os autores (2021). 


\begin{tabular}{|c|c|}
\hline Item original & Item adaptado \\
\hline Interface Positiva Trabalho-Família & Interface Positiva Estudos-Família \\
\hline $\begin{array}{l}\text { Os comportamentos exigidos no trabalho levam a comportamentos } \\
\text { que me ajudam na vida familiar. } \\
\text { As coisas que faço no trabalho me ajudam a lidar melhor com } \\
\text { questões pessoais e práticas em casa. } \\
\text { Os valores desenvolvidos no trabalho me tornam um membro } \\
\text { melhor da minha família. } \\
\text { Por causa do meu trabalho, eu me sinto capaz de ver os problemas } \\
\text { familiares sob diferentes perspectivas. }\end{array}$ & $\begin{array}{l}\text { Os comportamentos exigidos no meu ambiente acadêmico levam } \\
\text { a comportamentos que me ajudam na vida familiar. } \\
\text { As coisas que eu desenvolvo no ambiente acadêmico me ajudam a } \\
\text { lidar melhor com questões pessoais e práticas em casa. } \\
\text { Os valores desenvolvidos na minha vida acadêmica me tornam um } \\
\text { membro melhor na minha família. } \\
\text { Por causa dos meus estudos, eu me sinto capaz de ver os } \\
\text { problemas familiares sob diferentes perspectivas. }\end{array}$ \\
\hline $\begin{array}{l}\text { Cumprir as responsabilidades familiares se torna mais fácil através } \\
\text { do uso de comportamentos utilizados no trabalho. }\end{array}$ & $\begin{array}{l}\text { Cumprir as responsabilidades familiares se torna mais fácil através } \\
\text { do uso de comportamentos utilizados no ambiente acadêmico. }\end{array}$ \\
\hline $\begin{array}{l}\text { As habilidades que uso no trabalho me ajudam a lidar melhor com } \\
\text { questões familiares. } \\
\text { O meu envolvimento no trabalho me põe de bom humor e isto me } \\
\text { ajuda a ser um membro melhor da minha família. } \\
\text { O meu envolvimento no trabalho me ajuda a me sentir preenchido } \\
\text { como pessoa e isto me ajuda a ser um membro melhor da minha } \\
\text { família. } \\
\text { Eu aplico valores do meu local de trabalho em situações familiares. }\end{array}$ & $\begin{array}{l}\text { As habilidades que eu uso no ambiente acadêmico me ajudam a } \\
\text { lidar melhor com as questões familiares. } \\
\text { O meu envolvimento com a minha vida acadêmica me põe de bom } \\
\text { humor e isto me ajuda a ser um membro melhor da minha família. } \\
\text { O meu envolvimento com a minha vida acadêmica me ajuda a me } \\
\text { sentir preenchido como pessoa e isto me ajuda a ser um membro } \\
\text { melhor da minha família. } \\
\text { Eu aplico valores do espaço acadêmico em situações familiares. }\end{array}$ \\
\hline Interface Positiva Família-Trabalho & Interface Positiva Família-Estudos \\
\hline $\begin{array}{l}\text { Por causa de tudo que tenho a meu favor na minha família, meu } \\
\text { humor melhora no trabalho. } \\
\text { O meu envolvimento na família me põe de bom humor e isto me } \\
\text { ajuda a ser um trabalhador melhor. } \\
\text { O meu envolvimento na família faz eu me sentir contente e otimista } \\
\text { e isto me ajuda a ser um trabalhador melhor. } \\
\text { Valores que eu aprendi através de experiências familiares me ajudam } \\
\text { a cumprir minhas responsabilidades no trabalho. } \\
\text { O meu envolvimento na família me encoraja a usar o meu tempo no } \\
\text { trabalho com concentração e isto me ajuda a ser um trabalhador } \\
\text { melhor. } \\
\text { Por causa das coisas que aprendo no ambiente familiar, eu também } \\
\text { desenvolvo melhor meus contatos sociais no trabalho. } \\
\text { Comportamentos exigidos na minha vida familiar levam a } \\
\text { comportamentos que me ajudam no trabalho. } \\
\text { O meu envolvimento na família me ajuda a adquirir competências e } \\
\text { isto me ajuda a ser um trabalhador melhor. } \\
\text { As habilidades que eu uso em casa me ajudam a lidar melhor com os } \\
\text { problemas do trabalho. } \\
\text { Estar feliz em casa melhora o meu estado de espírito no trabalho. }\end{array}$ & $\begin{array}{l}\text { Por causa de tudo que eu tenho a meu favor na minha família, meu } \\
\text { humor melhora no meu cotidiano acadêmico. } \\
\text { O meu envolvimento na família me põe de bom humor e isto me } \\
\text { ajuda a ser um estudante melhor. } \\
\text { O meu envolvimento na família faz eu me sentir contente e otimista } \\
\text { e isto me ajuda a ser um estudante melhor. } \\
\text { Valores que eu aprendi através de experiências familiares me } \\
\text { ajudam a cumprir minhas responsabilidades acadêmicas. } \\
\text { O meu envolvimento na família me encoraja a usar o meu tempo } \\
\text { nos estudos e isto me ajuda a ser um estudante melhor. } \\
\text { Por causa das coisas que aprendo no ambiente familiar, eu } \\
\text { também desenvolvo melhor meus contatos sociais na vida } \\
\text { acadêmica. } \\
\text { Comportamentos exigidos na minha vida familiar levam a } \\
\text { comportamentos que me ajudam no ambiente acadêmico. } \\
\text { O meu envolvimento na família me ajuda a adquirir competências } \\
\text { e isto me ajuda a ser um estudante melhor. } \\
\text { As habilidades que eu uso em casa me ajudam a lidar melhor com } \\
\text { os problemas da vida acadêmica. } \\
\text { Estar feliz em casa melhora o meu estado de espírito no ambiente } \\
\text { acadêmico. }\end{array}$ \\
\hline
\end{tabular}

Fonte: Os autores (2021). 
Tabela 1. Índices de validade de conteúdo dos indicadores de Conflito Estudos-Família e alterações realizadas no processo de validação de conteúdo

\begin{tabular}{|c|c|c|}
\hline Conflito Estudos-Família & IVC & Decorrência \\
\hline $\begin{array}{l}\text { Meus estudos me afastam das minhas atividades familiares mais } \\
\text { tempo do que eu gostaria. }\end{array}$ & 1 & $\begin{array}{l}\text { Alterado para: Meus estudos me afastam de atividades } \\
\text { familiares mais tempo do que eu gostaria. }\end{array}$ \\
\hline $\begin{array}{l}\text { Eu muito frequentemente me sinto tão emocionalmente sugado(a) } \\
\text { pela minha vida acadêmica que isso me impede de contribuir com a } \\
\text { minha família. }\end{array}$ & 0,87 & $\begin{array}{l}\text { Alterado para: Eu me sinto tão emocionalmente } \\
\text { esgotado(a) por minha vida acadêmica que não consigo } \\
\text { contribuir com a minha família. }\end{array}$ \\
\hline $\begin{array}{l}\text { Os comportamentos que utilizo para solucionar problemas no } \\
\text { ambiente acadêmico não são efetivos para solucionar os problemas de } \\
\text { casa }\end{array}$ & 0,5 & $\begin{array}{l}\text { Alterado para: As estratégias que utilizo para solucionar } \\
\text { problemas no ambiente acadêmico não são efetivas na } \\
\text { solução dos problemas familiares. }\end{array}$ \\
\hline $\begin{array}{l}\text { O tempo que eu preciso me dedicar aos estudos me impede de } \\
\text { participar igualmente das atividades e responsabilidades em casa. }\end{array}$ & 0,75 & Excluído. \\
\hline $\begin{array}{l}\text { Quando eu concluo as minhas atividades acadêmicas, muitas vezes eu } \\
\text { já estou muito esgotado(a) para participar das atividades familiares. }\end{array}$ & 0,75 & $\begin{array}{l}\text { Alterado para: Quando eu finalizo as minhas atividades } \\
\text { acadêmicas, muitas vezes já estou muito esgotado(a) para } \\
\text { participar das atividades familiares. }\end{array}$ \\
\hline $\begin{array}{l}\text { Devido às pressões acadêmicas, algumas vezes eu chego em casa } \\
\text { muito estressado(a) para fazer as coisas que eu gosto. }\end{array}$ & 0,71 & Excluído. \\
\hline $\begin{array}{l}\text { Eu deixo de fazer coisas com a minha família devido ao tempo que } \\
\text { preciso dedicar às atividades acadêmicas. }\end{array}$ & 0,87 & Mantido. \\
\hline $\begin{array}{l}\text { Os comportamentos que desempenho para ser eficaz no ambiente } \\
\text { acadêmico não me ajudam a ser uma pessoa melhor para a minha } \\
\text { família (melhor filho/filha; pai/mãe; marido/esposa). }\end{array}$ & 0,62 & $\begin{array}{l}\text { Alterado para: As habilidades que desenvolvo no ambiente } \\
\text { acadêmico não me ajudam a ser uma pessoa melhor para } \\
\text { minha família (melhor filho/filha; pai/mãe; marido/esposa). }\end{array}$ \\
\hline Conflito Família-Estudos & IVC & Decorrência \\
\hline $\begin{array}{l}\text { O tempo que eu gasto com responsabilidades familiares } \\
\text { frequentemente interfere nas minhas responsabilidades acadêmicas }\end{array}$ & 1 & Mantido. \\
\hline $\begin{array}{l}\text { Devido ao estresse que vivo em casa, eu frequentemente fico } \\
\text { preocupado(a) com problemas familiares enquanto me dedico às } \\
\text { atividades acadêmicas. }\end{array}$ & 1 & $\begin{array}{l}\text { Alterado para: Eu fico preocupado(a) com problemas } \\
\text { familiares enquanto me dedico às atividades acadêmicas. }\end{array}$ \\
\hline $\begin{array}{l}\text { O tempo que passo com minha família frequentemente me impede de } \\
\text { dedicar tempo a atividades acadêmicas que poderiam ajudar na minha } \\
\text { carreira. }\end{array}$ & 0,85 & Mantido. \\
\hline $\begin{array}{l}\text { Como eu frequentemente estou estressado(a) por causa das minhas } \\
\text { responsabilidades familiares, eu tenho dificuldade de me concentrar } \\
\text { nos meus estudos. }\end{array}$ & 1 & $\begin{array}{l}\text { Alterado para: } 0 \text { estresse gerado por minhas } \\
\text { responsabilidades familiares dificulta minha concentração } \\
\text { nos estudos. }\end{array}$ \\
\hline $\begin{array}{l}\text { Os comportamentos que funcionam para mim em casa não são } \\
\text { eficazes no meu espaço acadêmico. }\end{array}$ & 0,87 & $\begin{array}{l}\text { Alterado para: As habilidades que funcionam para mim em } \\
\text { casa não são eficazes no meu espaço acadêmico. }\end{array}$ \\
\hline $\begin{array}{l}\text { A tensão e a ansiedade vindas da minha família frequentemente } \\
\text { enfraquecem minha capacidade de cumprir minhas atividades } \\
\text { acadêmicas. }\end{array}$ & 1 & Mantido. \\
\hline $\begin{array}{l}\text { Eu deixo de fazer atividades acadêmicas devido à quantidade de tempo } \\
\text { que preciso dedicar às minhas responsabilidades familiares. }\end{array}$ & 1 & Mantido. \\
\hline $\begin{array}{l}\text { Os comportamentos que uso para resolver problemas em casa não são } \\
\text { úteis no ambiente acadêmico. }\end{array}$ & 0,62 & $\begin{array}{l}\text { Alterado para: As estratégias que uso para resolver } \\
\text { problemas em casa não são úteis para solucionar } \\
\text { problemas no ambiente acadêmico. }\end{array}$ \\
\hline
\end{tabular}

Fonte: Os autores (2021). 
Tabela 2. Índices de validade de conteúdo dos indicadores de Interface Positiva Estudos-Família e alterações realizadas no processo de validação de conteúdo

\begin{tabular}{|c|c|c|}
\hline Interface positiva estudos-família & IVC & Decorrência \\
\hline $\begin{array}{l}\text { Os comportamentos exigidos no meu ambiente acadêmico levam a } \\
\text { comportamentos que me ajudam na vida familiar. }\end{array}$ & 0,87 & Mantido. \\
\hline $\begin{array}{l}\text { As coisas que eu desenvolvo no ambiente acadêmico me ajudam a lidar } \\
\text { melhor com questões pessoais e práticas em casa. }\end{array}$ & 0,71 & $\begin{array}{l}\text { Alterado para: As atividades que eu desenvolvo no } \\
\text { ambiente acadêmico me ajudam a lidar melhor com } \\
\text { questões pessoais e práticas em casa. }\end{array}$ \\
\hline $\begin{array}{l}\text { Os valores desenvolvidos na minha vida acadêmica me tornam um } \\
\text { membro melhor na minha família. }\end{array}$ & 0,87 & Mantido. \\
\hline $\begin{array}{l}\text { Por causa dos meus estudos, eu me sinto capaz de ver os problemas } \\
\text { familiares sob diferentes perspectivas. }\end{array}$ & 0,75 & Excluído. \\
\hline $\begin{array}{l}\text { Cumprir as responsabilidades familiares se torna mais fácil através do } \\
\text { uso de comportamentos utilizados no ambiente acadêmico. }\end{array}$ & 0,62 & $\begin{array}{l}\text { Alterado para: Cumprir as responsabilidades familiares se } \\
\text { torna mais fácil mediante ao uso de estratégias } \\
\text { empregadas no ambiente acadêmico. }\end{array}$ \\
\hline $\begin{array}{l}\text { As habilidades que eu uso no ambiente acadêmico me ajudam a lidar } \\
\text { melhor com as questões familiares. }\end{array}$ & 0,75 & Excluído. \\
\hline $\begin{array}{l}\text { O meu envolvimento com a minha vida acadêmica me põe de bom } \\
\text { humor e isto me ajuda a ser um membro melhor da minha família. }\end{array}$ & 1 & $\begin{array}{l}\text { Alterado para: Meu envolvimento com a vida acadêmica me } \\
\text { deixa de bom humor e isso me ajuda a ser um membro } \\
\text { melhor para minha família. }\end{array}$ \\
\hline $\begin{array}{l}\text { O meu envolvimento com a minha vida acadêmica me ajuda a me } \\
\text { sentir preenchido como pessoa e isto me ajuda a ser um membro } \\
\text { melhor da minha família. }\end{array}$ & 1 & $\begin{array}{l}\text { Alterado para: Meu envolvimento com a vida acadêmica me } \\
\text { ajuda a me sentir preenchido(a) como pessoa e isso me } \\
\text { ajuda a ser um membro melhor para minha família. }\end{array}$ \\
\hline Eu aplico valores do espaço acadêmico em situações familiares. & 0,75 & Excluído. \\
\hline Interface positiva estudos-família & IVC & Decorrência \\
\hline $\begin{array}{l}\text { Por causa de tudo que eu tenho a meu favor na minha família, meu } \\
\text { humor melhora no meu cotidiano acadêmico. }\end{array}$ & 0,75 & Excluído. \\
\hline $\begin{array}{l}\text { O meu envolvimento na família me põe de bom humor e isto me ajuda } \\
\text { a ser um estudante melhor. }\end{array}$ & 1 & Mantido. \\
\hline $\begin{array}{l}\text { O meu envolvimento na família faz eu me sentir contente e otimista e } \\
\text { isto me ajuda a ser um estudante melhor. }\end{array}$ & 1 & Mantido. \\
\hline $\begin{array}{l}\text { Valores que eu aprendi através de experiências familiares me ajudam } \\
\text { a cumprir minhas responsabilidades acadêmicas }\end{array}$ & 1 & Mantido. \\
\hline $\begin{array}{l}\text { O meu envolvimento na família me encoraja a usar o meu tempo nos } \\
\text { estudos e isto me ajuda a ser um estudante melhor }\end{array}$ & 1 & Mantido. \\
\hline $\begin{array}{l}\text { Por causa das coisas que aprendo no ambiente familiar, eu também } \\
\text { desenvolvo melhor meus contatos sociais na vida acadêmica }\end{array}$ & 1 & Mantido. \\
\hline $\begin{array}{l}\text { Comportamentos exigidos na minha vida familiar levam a } \\
\text { comportamentos que me ajudam no ambiente acadêmico. }\end{array}$ & 0,71 & Excluído. \\
\hline $\begin{array}{l}\text { O meu envolvimento na família me ajuda a adquirir competências e isto } \\
\text { me ajuda a ser um estudante melhor }\end{array}$ & 1 & Mantido. \\
\hline $\begin{array}{l}\text { As habilidades que eu uso em casa me ajudam a lidar melhor com os } \\
\text { problemas da vida acadêmica }\end{array}$ & 0,85 & Mantido. \\
\hline $\begin{array}{l}\text { Estar feliz em casa melhora o meu estado de espírito no ambiente } \\
\text { acadêmico }\end{array}$ & 1 & Mantido. \\
\hline
\end{tabular}

Fonte: Os autores (2021). 
O processo de adaptação das escalas finalizou-se com a análise semântica de uma pequena amostra de estudantes. As Tabelas 3 e 4 mostram o IVC de cada item e a partir desse número, o item foi mantido, excluído ou teve a sua escrita alterada.

Tabela 3. Índices de validade de conteúdo quanto à responsividade, clareza e objetividade decorrentes do processo de validação semântica da Escala de Conflito Estudos-Família

\begin{tabular}{|c|c|c|c|}
\hline Conflito Estudos-Família & IVC & IVC & IVC \\
\hline $\begin{array}{l}\text { Eu me sinto tão emocionalmente esgotado(a) por minha vida acadêmica que não consigo } \\
\text { contribuir com a minha família. }\end{array}$ & 0,95 & 0,72 & 0,86 \\
\hline $\begin{array}{l}\text { As estratégias que utilizo para solucionar problemas no ambiente acadêmico não são efetivas na } \\
\text { solução dos problemas familiares. }\end{array}$ & 0,81 & 0,63 & 0,63 \\
\hline $\begin{array}{l}\text { Quando eu finalizo as minhas atividades acadêmicas, muitas vezes já estou muito esgotado(a) } \\
\text { para participar das atividades familiares. }\end{array}$ & 1 & 0,95 & 0,95 \\
\hline $\begin{array}{l}\text { Eu deixo de fazer coisas com a minha família devido ao tempo que preciso dedicar às atividades } \\
\text { acadêmicas. }\end{array}$ & 1 & 0,90 & 0,95 \\
\hline $\begin{array}{l}\text { As habilidades que desenvolvo no ambiente acadêmico não me ajudam a ser uma pessoa melhor } \\
\text { para minha família (melhor filho/filha; pai/mãe; marido/esposa). }\end{array}$ & 0,90 & 0,86 & 0,81 \\
\hline \multirow{2}{*}{ Conflito Família-Estudos } & IVC & IVC & IVC \\
\hline & $\mathbf{R}$ & $\mathbf{C}$ & 0 \\
\hline Eu fico preocupado(a) com problemas familiares enquanto me dedico às atividades acadêmicas. & 1 & 1 & 0,95 \\
\hline $\begin{array}{l}\text { O tempo que passo com minha família frequentemente me impede de dedicar tempo a atividades } \\
\text { acadêmicas que poderiam ajudar na minha carreira. }\end{array}$ & 1 & 1 & 0,9 \\
\hline $\begin{array}{l}\text { O estresse gerado por minhas responsabilidades familiares dificulta minha concentração nos } \\
\text { estudos. }\end{array}$ & 1 & 1 & 1 \\
\hline As habilidades que funcionam para mim em casa não são eficazes no meu espaço acadêmico. & 0,54 & 0,54 & 0,54 \\
\hline $\begin{array}{l}\text { A tensão e a ansiedade vindas da minha família frequentemente enfraquecem minha capacidade } \\
\text { de cumprir minhas atividades acadêmicas. }\end{array}$ & 0,90 & 0,86 & 0,86 \\
\hline $\begin{array}{l}\text { Eu deixo de fazer atividades acadêmicas devido à quantidade de tempo que preciso dedicar às } \\
\text { minhas responsabilidades familiares. }\end{array}$ & 1 & 1 & 0,86 \\
\hline $\begin{array}{l}\text { As estratégias que uso para resolver problemas em casa não são úteis para solucionar problemas } \\
\text { no ambiente acadêmico. }\end{array}$ & 0,72 & 0,68 & 0,77 \\
\hline
\end{tabular}

$\mathrm{R}=$ Responsividade; $\mathrm{C}=$ Clareza; $\mathrm{O}=$ Objetividade

Fonte: Os autores (2021).

Após o processo de validação semântica da Escala de Conflito Estudos-Família, os itens que obtiveram pelo menos um valor de IVC abaixo de 0,78 foram reavaliados, optando-se pela exclusão dos itens: As estratégias que utilizo para solucionar problemas no ambiente acadêmico não são efetivas na solução dos problemas familiares e As habilidades que funcionam para mim em casa não são eficazes no meu espaço acadêmico. Além disso, dois outros itens sofreram modificações na sua escrita: o item Eu me sinto tão emocionalmente esgotado(a) por minha vida acadêmica que não consigo contribuir com a minha família foi alterado para As demandas da minha vida acadêmica me sugam emocionalmente de forma que eu não consigo contribuir do modo que gostaria com a minha família e o item As estratégias que uso para resolver problemas em casa não são úteis para solucionar problemas no ambiente acadêmico teve a sua redação alterada para As habilidades que desenvolvo no ambiente familiar não me ajudam a ser um estudante melhor. 
Tabela 4. Índices de validade de conteúdo quanto à responsividade, clareza e objetividade decorrentes do processo de validação semântica da Escala de Interface Positiva Estudos-Família

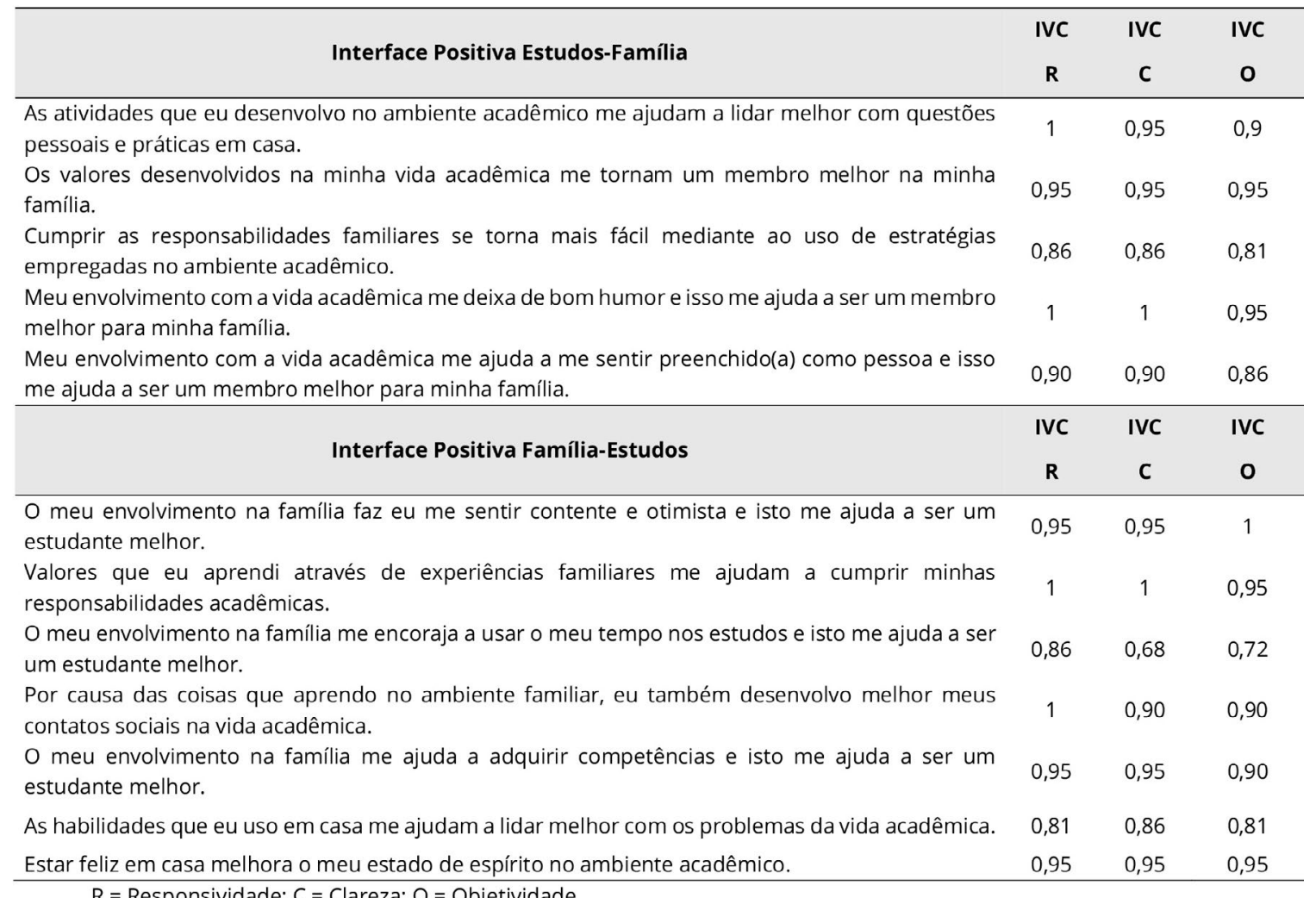

Fonte: Os autores (2021).

Da mesma forma que realizado com a Escala de Conflito Estudos-Família, o processo de validação semântica da Escala de Interface Positiva Estudos-Família culminou na reavaliação dos itens com valores de IVC abaixo de 0,78. Como pode ser observado na Tabela 4, apenas um item 0 meu envolvimento na família me encoraja a usar o meu tempo nos estudos e isto me ajuda a ser um estudante melhor não alcançou o valor minimamente satisfatório, sendo excluído.

\section{Etapa 2: Validação de Constructo e Consistência Interna}

Para esta etapa, a versão final do instrumento foi aplicada a uma amostra de 539 estudantes de medicina, distribuídos de acordo com as informações da Tabela 5. 
Tabela 5. Caracterização dos estudantes participantes das etapas de validação de constructo e consistência interna, no Brasil, no ano de 2020

\begin{tabular}{lc}
\hline & $\mathbf{N}(\%)$ \\
\hline Gênero & $398(73,8)$ \\
Feminino & $139(25,8)$ \\
Masculino & $2(0,4)$ \\
Outro & \\
Estado Civil & $503(93,3)$ \\
Solteiro(a) & $19(3,5)$ \\
Casado(a) & $9(1,7)$ \\
União estável & $2(0,4)$ \\
Divorciado(a) & $6(1,1)$ \\
Outro & \\
Ciclos & $177(32,7)$ \\
Básico & $295(54,6)$ \\
Clínico & $67(12,4)$ \\
Internato & \\
Idade & $23( \pm 4,0)$ anos \\
Média ( \pm DP) &
\end{tabular}

Fonte: Os autores (2021).

Na Escala de Conflito Estudos-Família, a matriz de correlações obtida apresentou KMO = 0,809 e o teste de esfericidade de Bartlett foi significativo $(p<0,001)$. O critério da raiz latente para decisão acerca do número de fatores a serem retidos ofereceu suporte para soluções compostas por até três fatores (Tabela 6).

Tabela 6. Fatores retidos pelo critério da raiz latente (Conflito)

\begin{tabular}{cccc}
\hline Fatores & Autovalor & $\%$ & \% Variância \\
& & Variância & Acumulada \\
1 & 4,155 & 34,622 & 34,622 \\
2 & 2,431 & 20,260 & 54,882 \\
3 & 1,179 & 9,826 & 64,708 \\
4 & 0,983 & 8,194 & 72,901 \\
5 & 0,679 & 5,657 & 78,559 \\
6 & 0,506 & 4,217 & 82,776 \\
7 & 0,475 & 3,958 & 86,734 \\
8 & 0,416 & 3,466 & 90,200 \\
9 & 0,392 & 3,268 & 93,468 \\
10 & 0,355 & 2,956 & 96,424 \\
11 & 0,249 & 2,072 & 98,496 \\
12 & 0,180 & 1,504 & 100,00 \\
\hline
\end{tabular}

Fonte: Os autores (2021).

Tendo em vista, entretanto, que a escala se baseia em um modelo teórico prévio que apresenta a previsão de dois fatores, optou-se pelo teste da solução bifatorial. As cargas fatoriais obtidas estão apresentadas na Tabela 7. 0 primeiro fator agrupou os sete itens referentes ao fator "Conflito Estudos-Família". O segundo fator reuniu cinco itens referentes ao fator "Conflito Família-Estudos". Não foram observados casos de cross-loadings (ambiguidade fatorial) ou de itens que não tenham obtido o valor mínimo (0.30) para serem alocados em um dos fatores. 


\begin{tabular}{|c|c|c|}
\hline & \multicolumn{2}{|c|}{ Fator } \\
\hline & 1 & 2 \\
\hline $\begin{array}{l}\text { 4. O estresse gerado por minhas responsabilidades familiares dificulta minha concentração nos } \\
\text { estudos. }\end{array}$ & 820 & \\
\hline $\begin{array}{l}\text { 5. A tensão e a ansiedade vindas da minha família frequentemente enfraquecem minha capacidade de } \\
\text { cumprir minhas atividades acadêmicas. }\end{array}$ & ,779 & \\
\hline $\begin{array}{l}\text { 3. O tempo que passo com minha família frequentemente me impede de dedicar tempo a atividades } \\
\text { acadêmicas que poderiam ajudar na minha carreira. }\end{array}$ & ,772 & \\
\hline $\begin{array}{l}\text { 6. Eu deixo de fazer atividades acadêmicas devido à quantidade de tempo que preciso dedicar às } \\
\text { minhas responsabilidades familiares. }\end{array}$ & ,766 & \\
\hline $\begin{array}{l}\text { 1. O tempo que eu gasto com responsabilidades familiares frequentemente interfere nas minhas } \\
\text { responsabilidades acadêmicas. }\end{array}$ & ,748 & \\
\hline 2. Eu fico preocupado(a) com problemas familiares enquanto me dedico às atividades acadêmicas. & ,650 & \\
\hline 7. As habilidades que desenvolvo no ambiente familiar não me ajudam a ser um estudante melhor. & ,468 & \\
\hline $\begin{array}{l}\text { 2. As demandas da minha vida acadêmica me sugam emocionalmente de forma que eu não consigo } \\
\text { contribuir do modo que gostaria com a minha família. }\end{array}$ & & 844 \\
\hline $\begin{array}{l}\text { 3. Quando eu finalizo as minhas atividades acadêmicas, muitas vezes já estou muito esgotado(a) para } \\
\text { participar das atividades familiares. }\end{array}$ & & 807 \\
\hline 1. Meus estudos me afastam de atividades familiares por mais tempo do que eu gostaria. & & ,789 \\
\hline $\begin{array}{l}\text { 4. Eu deixo de fazer coisas com a minha família devido ao tempo que preciso dedicar às atividades } \\
\text { acadêmicas. }\end{array}$ & & ,745 \\
\hline $\begin{array}{l}\text { 5. As habilidades que desenvolvo no ambiente acadêmico não me ajudam a ser uma pessoa melhor } \\
\text { para minha família (melhor filho/filha; pai/mãe; marido/esposa). }\end{array}$ & &, 410 \\
\hline
\end{tabular}

Fonte: Os autores (2021).

Para a análise da consistência interna, foram observados os indicadores alpha de Cronbach e a confiabilidade composta. O fator "Conflito Estudos-Família" (5 itens) apresentou alpha de 0,78 e índice de confiabilidade composta de 0,85. O fator "Conflito Família-Estudos" (7 itens), por sua vez, apresentou alpha de 0,85 e índice de confiabilidade composta de 0,88.

Com relação à Escala da Interface Positiva Estudos-Família, a matriz de correlações obtida apresentou KMO = 0,861 e o teste de esfericidade de Bartlett foi significativo $(p<0,001)$. O critério da raiz latente para decisão acerca do número de fatores a serem retidos ofereceu suporte para soluções compostas por até três fatores (Tabela 8).

Tabela 8. Fatores retidos pelo critério da raiz latente (Interface Positiva)

\begin{tabular}{cccc}
\hline Fatores & Autovalor & \% & \% Variância \\
& & Variância & Acumulada \\
2 & 5,568 & 42,827 & 42,827 \\
3 & 2,263 & 17,410 & 60,237 \\
4 & 1,061 & 8,161 & 68,398 \\
5 & 0,835 & 6,426 & 74,824 \\
6 & 0,673 & 5,178 & 80,002 \\
7 & 0,522 & 4,018 & 84,019 \\
8 & 0,464 & 3,565 & 87,585 \\
9 & 0,373 & 2,872 & 90,457 \\
10 & 0,331 & 2,550 & 93,006 \\
11 & 0,327 & 2,513 & 95,519 \\
12 & 0,276 & 2,126 & 97,645 \\
13 & 0,182 & 1,402 & 99,047 \\
\hline
\end{tabular}

Fonte: Os autores (2021). 
Sabendo, todavia, que a escala se baseia em um modelo teórico prévio que apresenta a previsão de dois fatores, optou-se pelo teste da solução bifatorial. As cargas fatoriais obtidas estão apresentadas na Tabela 9. O primeiro fator agrupou os sete itens referentes ao fator "Interface Positiva Família-Estudos". O segundo fator reuniu seis itens referentes ao fator "Interface Positiva Estudos-Família". Não foram observados casos de cross-loadings (ambiguidade fatorial) ou de itens que não tenham obtido o valor mínimo (0.30) para serem alocados em um dos fatores.

Tabela 9. Cargas Fatoriais - Solução bifatorial (Interface Positiva)

\begin{tabular}{|c|c|c|}
\hline & \multicolumn{2}{|c|}{ Fator } \\
\hline & 1 & 2 \\
\hline $\begin{array}{l}\text { 5. O meu envolvimento na minha família me ajuda a adquirir competências e isso me ajuda a ser um } \\
\text { estudante melhor. }\end{array}$ & ,868 & \\
\hline $\begin{array}{l}\text { 4. Por causa das coisas que aprendo no ambiente familiar, eu também desenvolvo melhor meus } \\
\text { contatos sociais na vida acadêmica. }\end{array}$ & ,836 & \\
\hline $\begin{array}{l}\text { 2. O meu envolvimento na família faz eu me sentir contente e otimista e isso me ajuda a ser um } \\
\text { estudante melhor. }\end{array}$ & ,789 & \\
\hline $\begin{array}{l}\text { 3. Valores que eu aprendi através de experiências familiares me ajudam a cumprir minhas } \\
\text { responsabilidades acadêmicas. }\end{array}$ & ,787 & \\
\hline 1. o meu envolvimento na família me põe de bom humor e isto me ajuda a ser um estudante melhor. & ,769 & \\
\hline 6. As habilidades que eu uso em casa me ajudam a lidar melhor com os problemas da vida acadêmica. & ,701 & \\
\hline 7. Estar feliz em casa melhora o meu estado de espírito no ambiente acadêmico. &, 580 & \\
\hline $\begin{array}{l}\text { 3. Os valores desenvolvidos na minha vida acadêmica me tornam um membro melhor na minha } \\
\text { família. }\end{array}$ & & ,788 \\
\hline $\begin{array}{l}\text { 2. As atividades que eu desenvolvo no ambiente acadêmico me ajudam a lidar melhor com questões } \\
\text { pessoais e práticas em casa. }\end{array}$ & & ,786 \\
\hline $\begin{array}{l}\text { 4. Cumprir as responsabilidades familiares se torna mais fácil mediante ao uso de estratégias } \\
\text { empregadas no ambiente acadêmico. }\end{array}$ & & ,758 \\
\hline $\begin{array}{l}\text { 1. Os comportamentos exigidos no meu ambiente acadêmico levam a comportamentos que me } \\
\text { ajudam na minha vida familiar. }\end{array}$ & & ,729 \\
\hline $\begin{array}{l}\text { 5. Meu envolvimento com a vida acadêmica me deixa de bom humor e isso me ajuda a ser um membro } \\
\text { melhor para minha família. }\end{array}$ & & ,724 \\
\hline $\begin{array}{l}\text { 6. Meu envolvimento com a vida acadêmica me ajuda a me sentir preenchido(a) como pessoa e isso } \\
\text { me ajuda a ser um membro melhor para minha família. }\end{array}$ & & ,677 \\
\hline
\end{tabular}

Fonte: Os autores (2021).

Para a análise da consistência interna, foram observados os indicadores alpha de Cronbach e a confiabilidade composta. O fator "Interface Positiva Família-Estudos" (7 itens) apresentou alpha de 0,90 e índice de confiabilidade composta de 0,91. O fator "Interface Positiva Estudos-Família" (6 itens), por sua vez, apresentou alpha de 0,85 e índice de confiabilidade composta de 0,88. 
Uma vez obtida a versão final das escalas, foram analisados de forma descritiva os resultados apresentados pelos estudantes de medicina. A média e o desvio padrão (DP) das dimensões e itens que compõem a Escala de Conflito Estudos-Família estão registrados na Tabela 10.

Tabela 10. Médias e DP das dimensões e itens que compõem a Escala de Conflito Estudos-Família

\begin{tabular}{|c|c|c|c|}
\hline Dimensões e Itens & $\mathbf{N}$ & Média & DP \\
\hline CONFLITO VIDA ACADÊMICA X VIDA FAMILIAR & 539 & 3,97 & 1,03 \\
\hline $\begin{array}{l}\text { CAF_1 Meus estudos me afastam de atividades familiares por mais tempo do } \\
\text { que eu gostaria. }\end{array}$ & 539 & 4,44 & 1,24 \\
\hline $\begin{array}{l}\text { CAF_2 As demandas da minha vida acadêmica me sugam emocionalmente de } \\
\text { forma que eu não consigo contribuir do modo que gostaria com a minha } \\
\text { família. }\end{array}$ & 539 & 4,14 & 1,40 \\
\hline $\begin{array}{l}\text { CAF_3 Quando eu finalizo as minhas atividades acadêmicas, muitas vezes já } \\
\text { estou muito esgotado(a) para participar das atividades familiares. }\end{array}$ & 539 & 4,12 & 1,52 \\
\hline $\begin{array}{l}\text { CAF_ } 4 \text { Eu deixo de fazer coisas com a minha família devido ao tempo que } \\
\text { preciso dedicar às atividades acadêmicas. }\end{array}$ & 539 & 4,65 & 1,30 \\
\hline $\begin{array}{l}\text { CAF_5 As habilidades que desenvolvo no ambiente acadêmico não me ajudam } \\
\text { a ser uma pessoa melhor para minha família (melhor filho/filha; pai/mãe; } \\
\text { marido/esposa). }\end{array}$ & 539 & 2,50 & 1,57 \\
\hline CONFLITO VIDA FAMILIAR X VIDA ACADÊMICA & 539 & 2,57 & 1,09 \\
\hline $\begin{array}{l}\text { CFA_1 O tempo que eu gasto com responsabilidades familiares } \\
\text { frequentemente interfere nas minhas responsabilidades acadêmicas. }\end{array}$ & 539 & 2,67 & 1,48 \\
\hline $\begin{array}{l}\text { CFA_2 Eu fico preocupado(a) com problemas familiares enquanto me dedico } \\
\text { às atividades acadêmicas. }\end{array}$ & 539 & 3,61 & 1,68 \\
\hline $\begin{array}{l}\text { CFA_3 } 0 \text { tempo que passo com minha família frequentemente me impede de } \\
\text { dedicar tempo a atividades acadêmicas que poderiam ajudar na minha } \\
\text { carreira. }\end{array}$ & 539 & 2,22 & 1,34 \\
\hline $\begin{array}{l}\text { CFA_4 O estresse gerado por minhas responsabilidades familiares dificulta } \\
\text { minha concentração nos estudos. }\end{array}$ & 539 & 3,01 & 1,72 \\
\hline $\begin{array}{l}\text { CFA_5 A tensão e a ansiedade vindas da minha família frequentemente } \\
\text { enfraquecem minha capacidade de cumprir minhas atividades acadêmicas. }\end{array}$ & 539 & 2,83 & 1,74 \\
\hline $\begin{array}{l}\text { CFA_6 Eu deixo de fazer atividades acadêmicas devido à quantidade de tempo } \\
\text { que preciso dedicar às minhas responsabilidades familiares. }\end{array}$ & 539 & 1,88 & 1,22 \\
\hline $\begin{array}{l}\text { CFA_7 As habilidades que desenvolvo no ambiente familiar não me ajudam a } \\
\text { ser um estudante melhor. }\end{array}$ & 539 & 1,75 & 1,23 \\
\hline
\end{tabular}

Fonte: Os autores (2021). 
De forma semelhante, a média e o desvio padrão (DP) das dimensões e itens que compõem a Escala de Interface Positiva Estudos-Família estão apresentados na Tabela 11.

Tabela 11. Médias e DP das dimensões e itens que compõem a Escala de Interface Positiva Estudos-Família

\begin{tabular}{|c|c|c|c|}
\hline Dimensões e Itens & $\mathbf{N}$ & Média & DP \\
\hline INTERFACE POSITIVA VIDA ACADÊMICA X VIDA FAMILIAR & 539 & 3,96 & 1,06 \\
\hline $\begin{array}{l}\text { IPAF_1 Os comportamentos exigidos no meu ambiente acadêmico levam a } \\
\text { comportamentos que me ajudam na vida familiar. }\end{array}$ & 539 & 4,33 & 1,34 \\
\hline $\begin{array}{l}\text { IPAF_2 As atividades que eu desenvolvo no ambiente acadêmico me ajudam } \\
\text { a lidar melhor com questões pessoais e práticas em casa. }\end{array}$ & 539 & 4,33 & 1,29 \\
\hline $\begin{array}{l}\text { IPAF_3 Os valores desenvolvidos na minha vida acadêmica me tornam um } \\
\text { membro melhor na minha família. }\end{array}$ & 539 & 4,44 & 1,30 \\
\hline $\begin{array}{l}\text { IPAF_4 Cumprir as responsabilidades familiares se torna mais fácil mediante } \\
\text { ao uso de estratégias empregadas no ambiente acadêmico. }\end{array}$ & 539 & 3,59 & 1,47 \\
\hline INTERFACE POSITIVA VIDA ACADÊMICA X VIDA FAMILIAR & 539 & 3,96 & 1,06 \\
\hline $\begin{array}{l}\text { IPAF_5 Meu envolvimento com a vida acadêmica me deixa de bom humor e } \\
\text { isso me ajuda a ser um membro melhor para minha família. }\end{array}$ & 539 & 3,12 & 1,49 \\
\hline $\begin{array}{l}\text { IPAF_6 Meu envolvimento com a vida acadêmica me ajuda a me sentir } \\
\text { preenchido(a) como pessoa e isso me ajuda a ser um membro melhor para } \\
\text { minha família. }\end{array}$ & 539 & 3,93 & 1,50 \\
\hline INTERFACE POSITIVA VIDA FAMILIAR X VIDA ACADÊMICA & 539 & 4,95 & 0,964 \\
\hline $\begin{array}{l}\text { IPFA_1 O meu envolvimento na família me põe de bom humor e isto me } \\
\text { ajuda a ser um estudante melhor. }\end{array}$ & 539 & 4,47 & 1,37 \\
\hline $\begin{array}{l}\text { IPFA_2 O meu envolvimento na família faz eu me sentir contente e otimista } \\
\text { e isso me ajuda a ser um estudante melhor. }\end{array}$ & 539 & 4,49 & 1,44 \\
\hline $\begin{array}{l}\text { IPFA_3 Valores que eu aprendi através de experiências familiares me } \\
\text { ajudam a cumprir minhas responsabilidades acadêmicas. }\end{array}$ & 539 & 5,38 & 1,07 \\
\hline $\begin{array}{l}\text { IPFA_4 Por causa das coisas que aprendo no ambiente familiar, eu também } \\
\text { desenvolvo melhor meus contatos sociais na vida acadêmica. }\end{array}$ & 539 & 5,03 & 1,25 \\
\hline $\begin{array}{l}\text { IPFA_5 } 0 \text { meu envolvimento na família me ajuda a adquirir competências e } \\
\text { isso me ajuda a ser um estudante melhor. }\end{array}$ & 539 & 4,97 & 1,24 \\
\hline $\begin{array}{l}\text { IPFA_6 As habilidades que eu uso em casa me ajudam a lidar melhor com os } \\
\text { problemas da vida acadêmica. }\end{array}$ & 539 & 4,72 & 1,32 \\
\hline $\begin{array}{l}\text { IPFA_7 Estar feliz em casa melhora o meu estado de espírito no ambiente } \\
\text { acadêmico. }\end{array}$ & 539 & 5,60 & 0,84 \\
\hline
\end{tabular}

Fonte: Os autores (2021).

Foi realizada de forma comparativa a percepção das interfaces entre a vida acadêmica e a vida familiar de acordo com os ciclos (básico, clínico e internato) do curso, conforme demonstra a Tabela 12.

Tabela 12. Comparação das interfaces entre vida acadêmica e familiar de acordo com o ciclo do curso

\begin{tabular}{|c|c|c|c|c|}
\hline & $\begin{array}{c}\text { Ciclo Básico } \\
\text { (N=177) }\end{array}$ & $\begin{array}{l}\text { Ciclo Clínico } \\
(\mathrm{N}=295)\end{array}$ & $\begin{array}{l}\text { Internato } \\
(\mathrm{N}=67)\end{array}$ & \\
\hline & Média (DP) & Média (DP) & Média (DP) & $\mathbf{p}$ \\
\hline Conflito Vida Acadêmica X Vida Familiar & $4,08(0,10)^{\mathrm{a}}$ & $3,97(1,04)$ & $3,66(0,95)^{a}$ & 0,015 \\
\hline Conflito Vida Familiar X Vida Acadêmica & $2,61(1,05)$ & $2,47(1,10)^{b}$ & $2,88(1,09)^{b}$ & 0,015 \\
\hline $\begin{array}{l}\text { Interface Positiva Vida Acadêmica X Vida } \\
\text { Familiar }\end{array}$ & $4,07(1,16)^{c}$ & $3,97(1,01)$ & $3,63(0,94)^{c}$ & 0,014 \\
\hline $\begin{array}{c}\text { Interface Positiva Vida Familiar X Vida } \\
\text { Acadêmica }\end{array}$ & $4,95(0,98)^{d}$ & $5,02(0,95)^{\mathrm{e}}$ & $4,62(0,91)^{\mathrm{d}, \mathrm{e}}$ & 0,008 \\
\hline
\end{tabular}

$a=0,011 ; b=0,015 ; c=0,011 ; d=0,047 ; e=0,006$

Fonte: Os autores (2021). 


\section{Discussão}

Como primeira etapa da presente pesquisa, foi realizada a adaptação para o contexto acadêmico de duas escalas originalmente propostas para avaliar as interfaces entre trabalho e família. A versão adaptada passou pelas fases de validação de conteúdo e semântica. Em ambas as fases, ajustes foram realizados, envolvendo modificações na escrita de alguns itens e, ainda, a exclusão de outros.

Em seguida, as versões finais dos instrumentos foram aplicadas a uma amostra de 539 estudantes de medicina, possibilitando a análise da validade de constructo (por meio da AFE) e da confiabilidade (utilizando os índices de confiabilidade composta e alpha de Cronbach). Os resultados da AFE indicaram que os instrumentos foram capazes de mensurar de forma satisfatória os fenômenos propostos. Todos os itens testados nessa etapa obtiveram cargas fatoriais elevadas nos fatores previstos teoricamente. Ademais, não houve necessidade de exclusão de itens. É possível atribuir a boa qualidade dos itens, em grande medida, ao processo cuidadoso conduzido nas etapas de adaptação das escalas originais e de validação de conteúdo e semântica. Borsa e Seize ${ }^{11}$ destacam essas etapas como cruciais no processo de construção ou adaptação de instrumentos psicométricos.

Para a análise da consistência interna dos fatores, foram conduzidas análises de confiabilidade composta e de alpha de Cronbach. Apesar de o índice alpha de Cronbach ainda ser mais amplamente utilizado como indicador de consistência, algumas restrições a seu uso têm sido apontadas na literatura (como o fato de ser fortemente afetado pela extensão do teste). ${ }^{12}$ Por essa razão, optou-se pelo uso conjunto com o índice de confiabilidade composta, que tem sido apresentado como um indicador de precisão mais robusto. $\frac{13}{}$ Todos os índices obtidos foram considerados elevados.

Em síntese, os resultados alcançados sugerem que as escalas têm uma qualidade psicométrica satisfatória, sendo, portanto, uma ferramenta capaz de mensurar adequadamente a percepção de estudantes de medicina sobre as interfaces - positivas e negativas - estabelecidas entre a vida acadêmica e a vida familiar. Diante disso, foi possível prosseguir para a segunda fase do estudo, que pretendeu descrever a percepção sobre as interfaces estabelecidas entre a vida acadêmica e a vida familiar de estudantes de medicina e, ainda, comparar o grau de interferência entre o estudo e a família de acordo com o ciclo do curso em que o estudante se encontra.

De acordo com os dados obtidos, percebe-se que a maioria dos estudantes que participaram do estudo são do sexo feminino, em concordância com o fenômeno global de inserção feminina na medicina. ${ }^{14}$ As mulheres já representam a maioria entre médicos mais jovens, e isso tem grande impacto na formação de novas configurações familiares a partir do que as mulheres credenciam nas suas vidas profissionais. $\frac{15}{}$

Com relação ao estado civil, a maioria dos estudantes se identificou como solteiro. Isso ocorre devido ao fato de que nos cursos de graduação em geral há mais indivíduos jovens. Observa-se ainda que a média de idade dos participantes foi de 23 anos, semelhante à média de idade dos estudantes de uma universidade do Pará que foi de $22 \operatorname{anos}^{16}$ e dos graduandos de uma faculdade do Rio Grande do Norte com a média de 23 anos. ${ }^{17}$ A pesquisa "Demografia Médica no Brasil 2018" demonstra um processo de rejuvenescimento do exercício médico no Brasil, com a média de idade dos profissionais diminuindo ao longo dos anos. Essa nova estrutura tem como causa a abertura de novos cursos nos estados brasileiros permitindo a entrada de médicos mais jovens. ${ }^{18}$

No que diz respeito à Escala de Conflito EstudosFamília, os alunos, em geral, percebem que a vida acadêmica traz mais prejuízo à vida familiar do que o inverso. O item com a maior média foi: "Eu deixo de fazer coisas com a minha família devido ao tempo que preciso dedicar às atividades acadêmicas". O curso de medicina no Brasil tem como carga horária mínima definida pelo Ministério da Educação 7200 horas. ${ }^{19}$ Sabe-se que além das aulas presenciais e obrigatórias, o curso requer tempo para estudo, tempo para atividades extracurriculares que são indispensáveis para a formação, o que acaba por exigir do graduando uma quantidade excessiva de tempo da sua rotina. Essa dedicação priva muitas vezes o estudante de praticar atividades físicas, de lazer e compromete a sua vida afetiva e social. 20

No que se refere à Escala de Conflito Família-Estudos, é possível constatar que os participantes identificaram um prejuízo moderado da vida familiar nos estudos. É frequente que o estresse psicológico se manifeste como inabilidade de concentração em outros assuntos que não estejam relacionados ao fator estressor, dessa forma, a tensão familiar interfere na 
performance dos estudantes ${ }^{21}$, coincidindo com o item de maior média na referida escala: "Eu fico preocupado(a) com problemas familiares enquanto me dedico às atividades acadêmicas".

Com relação à Escala de Interface Positiva, pode-se perceber que a família gera um impacto positivo maior na vida acadêmica, do que o processo inverso. Além disso, o fenômeno mais verificado pelos participantes do estudo foi a interface positiva da vida familiar na vida acadêmica. Tendo em vista o papel formativo da família na vida do sujeito, é natural que os princípios e valores aprendidos em casa sirvam como base para a construção de uma vida social e profissional sólida e estruturada. Dentro de todos os itens propostos pelo instrumento de pesquisa, aquele que obteve uma maior média foi: "Estar feliz em casa melhora o meu estado de espírito no ambiente acadêmico". Isso é reflexo da importante função da família na produção de vínculos e de relações de cuidado e conflito, que possibilitam aos indivíduos se sentirem pertencentes a um grupo, bem como a ampliar as orientações familiares aprendidas em outras estruturas sociais. $\underline{\underline{22}}$

Quando se trata da percepção do conflito e da interface positiva estudos-família ao longo do curso, observa-se que existem diferenças estatisticamente significantes a partir do momento do curso em que esses indivíduos estão inseridos. O ciclo básico, que corresponde aos primeiros dois anos do curso, é o grupo que observa o maior conflito da vida acadêmica na família. Tal fenômeno pode ser explicado pelo fato de que o ingresso no ensino superior é marcado por um momento de transição na vida dos estudantes, que gera repercussões potenciais no desenvolvimento psicológico deles. Esse momento representa comumente a primeira tentativa de independência individual através da escolha profissional. A entrada na faculdade também gera mudanças na rede social de apoio dos jovens, revelando transformações nas amizades, nas figuras de exemplos e na família. Sabe-se que todas essas rupturas que o início da vida universitária traz gera significativas mudanças no convívio familiar dos estudantes. ${ }^{23}$ No entanto, o ciclo básico também é aquele que mais percebe a interface positiva da vida acadêmica na família, gerando certo equilíbrio entre o prejuízo identificado nos primeiros anos de curso.
Por outro lado, quando se coloca o conflito gerado pela família prejudicando os estudos, os alunos do internato, que equivale aos dois últimos anos do curso de medicina, são aqueles que mais constatam esse fenômeno. Esses estudantes estão se preparando para as provas de residência, que representam a grande escolha profissional deles, então, muitas vezes eles abdicam de certas atividades sociais para estudar. Além disso, são indivíduos que manifestam ansiedade, medo e insegurança em relação ao futuro profissional e à inserção no mercado de trabalho. ${ }^{24}$

O ciclo clínico, período compreendido no meio da graduação que são o terceiro e o quarto ano, é marcado por um momento de maior estabilidade no curso. Os vínculos já foram criados, não há tanta preocupação com a mudança profissional em um futuro próximo, como ocorre no internato, e dessa forma, a família configura como um importante ponto de equilíbrio para essas pessoas. Sabe-se que o ciclo clínico é aquele em que há menos indicadores de estresse por parte dos estudantes $\frac{25}{}$, e isso ocorre em virtude desse momento de o curso simbolizar o melhor período de adaptação em relação aos extremos (início e fim), bem como pelo fato da rede de apoio desses estudantes estar bem consolidada, sendo assim, eles identificam em maior grau a influência positiva da família na vida acadêmica.

Reconhece-se como restrição o fato de o instrumento ter sido aplicado em uma amostra de estudantes majoritariamente de um único estado do país. Além disso, apesar de realizados esforços para que fosse possível a participação de várias instituições de ensino com diversas características socioeconômicas, culturais, regionais, é provável que os dados obtidos tenham sofrido vieses da cultura da amostra, além de que não houve itens que caracterizassem o perfil sociodemográfico dos estudantes, e isso determina limitações na generalização dos resultados obtidos.

Associado a isso, não é possível desconsiderar que a pesquisa foi atravessada por um período de pandemia, em que ocorreu a mudança do ambiente de aprendizado: os estudantes passaram a realizar as suas atividades acadêmicas em casa, dividindo, dessa forma, de maneira mais próxima e intensa, a vida acadêmica com a vida familiar. Reconhece-se, então, que isso pode ter gerado um perfil de respostas diferente do que poderia ter sido obtido em situações de ausência de pandemia e isolamento social. 
Como primeiro trabalho de pesquisa a tratar da relação entre a vida acadêmica e a vida familiar dos estudantes de medicina, acredita-se que o pioneirismo possa incentivar futuros pesquisadores a investigar o tema e expandi-lo em outros momentos da vida acadêmica dos sujeitos, como por exemplo, alunos de pós-graduação, bem como outros cursos de graduação. Isso permitirá avaliar os fenômenos de conflito e interface positiva entre estudos e família em outras realidades, além de conferir maior validade aos instrumentos.

\section{Conclusões}

- Os instrumentos propostos mostraram-se válidos e confiáveis para mensurar as interfaces positiva e negativa entre a vida acadêmica e a vida familiar de estudantes.

- Os estudantes de medicina identificam uma maior influência da vida acadêmica prejudicando a vida familiar e percebem a família contribuindo mais nos estudos de maneira favorável.

- Alunos do ciclo básico apresentaram maior percepção de que o estudo prejudica suas atividades familiares; alunos do internato foram os que mais perceberam a família prejudicando a vida acadêmica; por fim, o ciclo clínico se revelou o momento de maior equilíbrio entre a vida acadêmica e a vida familiar.

\section{Contribuições dos autores}

Aguiar CVN participou da orientação, análise dos dados, produção textual e correção do estudo. Reis SB participou da análise dos dados e produção textual.

\section{Conflitos de interesses}

Nenhum conflito financeiro, legal ou político envolvendo terceiros (governo, empresas e fundações privadas etc.) foi declarado para nenhum aspecto do trabalho submetido (incluindo, mas não se limitando a subvenções e financiamentos, participação em conselho consultivo, desenho de estudo, preparação de manuscrito, análise estatística etc.).

\section{Referências}

1. Resolução $n^{\circ}$ 3, de 20 de junho de 2014 (Brasil). Institui Diretrizes Curriculares Nacionais do Curso de Graduação em Medicina e dá outras providências. [Internet]. Diário Oficial da União. 2014 jun 3. Disponível em: https://faceres.com.br/cursos/ medicina/diretrizes-curriculares-nacionais-medicina-de-2014

2. Hwang IC, Park KH, Kim JJ, Yim J, Ko KP, Bae SM, et al. Perceived Social Support as a Determinant of Quality of Life among Medical Students: 6-Month Follow-up Study. Acad Psychiatry. 2017;41(2):180-4. https://doi.org/10.1007/s40596-016-0503-5

3. Silva F. Família e ensino superior: que relação entre dois contextos de desenvolvimento? Exedra [Internet]. 2009;1:101-26. Disponível em: http://dialnet.unirioja.es/servlet/ articulo?codigo $=3398329$

4. Aguiar CVN. Interfaces entre o trabalho e a família e os vínculos organizacionais: explorando a tríade família-trabalho-organização [dissertação] [Internet]. Salvador: Universidade Federal da Bahia; 2016. Disponível em: https://pospsi.ufba.br/sites/pospsi.ufba.br/ files/carolina_villa_nova_tese.pdf

5. Aguiar CVN, Bastos AVB. Interface positiva trabalho e família: proposta de instrumento e evidências de validade. 2017;17(1):4858. http://dx.doi.org/10.15689/ap.2017.1701.06.13175

6. Sanchez HM, Sbroggio Jr AL, Morais EG, Agostinho PLS, Poloniato TB, Soares PG. Avaliação da qualidade de vida de médicos clínicos e cirurgiões. Rev Bras Promoç Saúde [Internet]. 2018;31(3):1-9. Disponível em: https://periodicos.unifor.br/RBPS/ article/download/7582/pdf_1

7. Alexandre NMC, Coluci MZO. Validade de conteúdo nos processos de construção e adaptação de instrumentos de medidas. Ciênc. saúde coletiva. 2011;16(7):3061-8. https://doi. org/10.1590/S1413-81232011000800006

8. Polit DF, Beck CT. The content validity index: are you sure you know what's being reported? Critique and recommendations. Res Nurs Health 2006;29(5):489-97. https://doi.org/10.1002/nur.20147

9. Echevarría-Guanilo ME, Gonçalves N. Propriedades psicométricas de instrumentos de medidas: bases conceituais e métodos de avaliação - parte ii. Texto Contexto enferm. 2017;16(5):270-6. http://dx.doi.org/10.1590/010407072017001600017

10. Peterson RA, Kim Y. On the relationship between coefficient alpha and composite reliability. J Appl Psychol. 2013;98(1):194-8. https://doi.apa.org/doiLanding?doi=10.1037\%2Fa0030767

11. Damásio B, Borsa J. Manual de desenvolvimento de instrumentos psicológicos. São Paulo: Vetor; 2017. 
12. Silva FC, Gonçalves E, Arancibia BA, Bento GG, Castro TL, Hernandez SS, et al. Estimadores de consistencia interna en las investigaciones en salud: el uso del coeficiente alfa. Rev Peru Med Exp Salud Publica [Internet]. 2015;32(1):129-38. http://www.scielo. org.pe/pdf/rins/v32n1/a19v32n1.pdf

13. Valentini F, Damásio BF. Variância Média Extraída e Confiabilidade Composta: Indicadores de Precisão. Psic.: Teor e Pesq. 2016;32(2):1-7. https://doi.org/10.1590/0102-3772e322225

14. Scheffer MC, Cassenote AJF. A feminização da medicina no Brasil [Internet]. Rev Bioét. 2013;21(2):26877. Disponível em: https://www.scielo.br/j/bioet/a/ XtCnKjggnr6gFR3bTRckCxs/?lang=pt

15. Ávila RC. Formação das Mulheres nas Escolas de Medicina. Rev. bras. educ. med. 2014;38(1):142-9. https://doi.org/10.1590/ s0100-55022014000100019

16. Rego RM, Marques NA, Monteiro PC, Oliveira CLB, Lins NAA, Caldas CAM. O perfil atual do estudante de Medicina e sua repercussão na vivência do curso. Para Res Med J. 2018;2(1 40):e05. http://dx.doi.org/10.4322/prmj.2018.005

17. Cardoso Filho FAB, Magalhães JF, Silva KML, Pereira ISSD. Perfil do Estudante de Medicina da Universidade do Estado do Rio Grande do Norte (UERN), 2013. Rev Bras Educ Med. 2015;39(1):3240. https://doi.org/10.1590/1981-52712015v39n1e01092014

18. Scheffer M, Cassenote A, Guilloux AGA, Biancarelli A, Miotto BA, Mainardi GM. Demografia médica no Brasil 2018 [Internet]. São Paulo: FMUSP, CFM, Cremesp; 2018. Disponível em: https:// jornal.usp.br/wp-content/uploads/DemografiaMedica2018.pdf
19. Simães C. Conflito trabalho-família em profissionais de saúde: teoria, investigação e intervenção. In: Bartholomeu $D$, Montiel JM, Machado AA, Gomes AR, Couto G, Cassep-Borges V, editores. Relações interpessoais: Concepções e contextos de intervenção e avaliação. São Paulo: Vetor; 2016. p. 205-234

20. Deng S, Yang N, Li S, Wang W, Yan H, Li H. Doctors' job satisfaction and its relationships with doctor-patient relationship and work-family conflict in China: A structural equation modeling. Inq (United States). 2018;55(1-11). https://doi. org/10.1177/0046958018790831

21. Monteiro CFS, Freitas JFM, Ribeiro AAP. Estresse no cotidiano acadêmico: o olhar dos alunos de Enfermagem da Universidade Federal do Piauí. Esc. Anna Nery. 2007;11(1):66-72. https://doi. org/10.1590/S1414-81452007000100009

22. Dunningham WA. Saúde mental. Rev. bras. neurol. psiquiatr. 2016;20(3):186. Disponível em: https://www.revneuropsiq.com.br/ rbnp/article/download/262/102

23. Teixeira MAP, Dias ACG, Wottrich SH, Oliveira AM. Adaptação à universidade em jovens calouros. Psicol Esc Educ. 2008;12(1):185202. https://doi.org/10.1590/S1413-85572008000100013

24. Costa DS, Medeiros NSB, Cordeiro RA, Frutuoso ES, Lopes JM, Moreira SNT. Sintomas de Depressão, Ansiedade e Estresse em Estudantes de Medicina e Estratégias Institucionais de Enfrentamento. 2020;44(1):1-10. https://doi.org/10.1590/19815271v44.1-20190069

25. Santos FS, Maia CRC, Faedo FC, Gomes GPC, Nunes ME, Oliveira MVM. Estresse em Estudantes de Cursos Preparatórios e de Graduação em Medicina. Rev bras educ med. 2017;41(2):194200. https://doi.org/10.1590/1981-52712015v41n2RB20150047 